\title{
NOVOS TEMPOS, VELHO REMÉDIO? OS RISCOS DA CLÁUSULA DEMOCRÁTICA NO SISTEMA INTERAMERICANO DE DIREITOS HUMANOS
}

\author{
NEW TIMES, OLD REMEDY? THE RISKS OF THE DEMOCRATIC CLAUSE IN THE \\ INTER-AMERICAN HUMAN RIGHTS SYSTEM
}

\begin{abstract}
André de Carvalho Ramos
É Professor da Faculdade de Direito da Universidade de São Paulo (USP - Largo São Francisco). É Professor Titular do Programa de Pós-Graduação Stricto Sensu Mestrado e Doutorado - da Faculdade Autônoma de Direito (FADISP). É Livre-Docente e Doutor em Direito Internacional pela Faculdade de Direito da Universidade de São Paulo. Foi visiting fellow do Lauterpacht Centre for International Law (Cambridge). É Procurador Regional da República.
\end{abstract}

\section{Resumo}

Este artigo analisa criticamente a promoção da democracia pelo olhar do direito internacional, com base no mecanismo interamericano da chamada "cláusula democrática", com foco em sua atuação tanto diante da ruptura "clássica" da democracia (golpe militar) quanto das novas crises geradas pelo uso de julgamento políticos para interromper mandatos de presidentes tidos como impopulares.

Palavras-chave: direitos humanos, democracia, Organização dos Estados Americanos, golpe militar, impeachment.

\begin{abstract}
This article critically analyzes the promotion of democracy through the eyes of international law, based on the inter-American mechanism of the so-called "democratic clause", focusing on its action both in the face of the "classic" breakdown of democracy (military coup) and the new crises generated by the use of political judgment to interrupt mandates of presidents deemed unpopular.

Key-words: human rights, democracy, Organization of American States, military coup, impeachment.
\end{abstract}




\section{INTRODUÇÃO: NOVOS TEMPOS, VELHO REMÉDIO?}

A legitimidade de uma investidura popular não assegura, na América Latina, o exercício do mandato presidencial em toda sua duração. De acordo com estudo de Hochstetler voltado para a América do Sul, entre 1970 e 2003, dos 40 presidentes eleitos por voto direto, 16 deles enfrentaram contestações à permanência no cargo $(40 \%)$ e $9(23 \%)$ tiveram seus mandatos interrompidos ${ }^{1}$.

Entre 1992 e 2004, seis presidentes eleitos na região sofreram processos de impeachment: Fernando Collor (Brasil, 1992); Carlos Andrés Perez (Venezuela, 1993; Ernesto Samper (Colômbia, 1996); Abdala Bucáram (Equador, 1997); Raul Cubas e Gonzalez Machi, ambos do Paraguai (1999 e 2003). E, ainda, vários renunciam ou abandonaram seu posto diante de fortes contestações políticas: Fujimori (fugiu do Peru, 2000), Jamil Mahuad Witt (solicitou refúgio na Embaixada do Chile e depois apoiou a posse do seu Vice; Equador, 2000²) Lucio Gutierrez (Equador, 2005), Fernando de la Rua (Argentina, 2001), Gonzalo Sanchez de Louzada e Carlos Mesa, ambos da Bolívia (2003 e 2005) $)^{3}$. Na década seguinte, houve processo contra Fernando Lugo (Paraguai, 2012) e Dilma Rousseff (Brasil, 2016).

Não surpreende, então, que, mesmo após a redemocratização dos Estados americanos nos anos 80 do século passado ${ }^{4}$, a defesa da democracia continue sendo uma das prioridades da Organização dos Estados Americanos (OEA) no século XXI, que busca, assim, proteger tanto os direitos à participação política quanto os demais direitos humanos que só vicejam em um ambiente democrático.

\footnotetext{
${ }^{1}$ HOCHSTETLER, Kathryn. Repensando o presidencialismo: contestações e quedas de presidentes na América do Sul. Lua Nova, n.72, 2007, pp.09-46, em especial p. 11.

2 A deposição do Presidente Mahuad deu-se após levante indígena com apoio de parte das Forças Armadas, liderada pelo Coronel Lucio Gutierrez. O apoio do Presidente deposto à posse do VicePresidente Gustavo Noboa explica o motivo pelo qual não houve acionamento da cláusula democrática da OEA (ver abaixo). Ver mais no relatório sobre o Equador da Comissão Interamericana de Direitos Humanos, de abril de 2000, em especial parágrafo 43, que justifica a falta de apoio ao retorno do Sr. Mahuad. OEA, Comissão Interamericana de Direitos Humanos, Relatório sobre o Equador, 2000. Disponível em http://www.cidh.oas.org/annualrep/99eng/Chapter4a.htm, acesso em 13-07-2020.

${ }^{3}$ Rol elaborado por Mendes, com exceção do Presidente Mahuad. MENDES, Gabriel Gutierrez. O impeachment de Dilma Rousseff e a instabilidade política na América Latina: a aplicabilidade do modelo de Perez-Liñan. Revista de Ciências Sociais, v.49, n. 1, p.55-97, mar./jun., 2018, pp. 253-278, em especial pp. 253-254

4 Huntington denomina $\mathrm{o}$ fim das diversas ditaduras latino-americanas e o processo de redemocratização na região de uma "onda" (seria a terceira), na qual as ditaduras foram substituídas por regimes democráticos, após severas crises econômicas e sociais nos anos 80 do século passado. HUNTINGTON, Samuel P. The Third Wave - Democratization in the Late Twentieth Century. Norman/London : University of Oklahoma Press, 1993. Ver também HAGOPIAN, Frances e MAINWARING, Scott P. (orgs). The Third Wave of Democratization in Latin America - Advances and setbacks. Cambridge/New York: Cambridge University Press, 2005.
}

Revista de Direitos Fundamentais \& Democracia, Curitiba, v. 25, n. 3, p. 5-31, set./dez. 2020 
Assim, o presente artigo propõe um estudo renovado da promoção da democracia pelo olhar do direito internacional, com base na ação de determinados mecanismos manejados pela Organização dos Estados Americanos.

Optou-se pela análise do mecanismo interamericano da chamada "cláusula democrática"5, com foco em seu uso tanto diante da ruptura "clássica" da democracia (golpe militar) quanto diante das novas crises geradas pelo uso de julgamento políticos para interromper mandatos de presidentes tidos como impopulares.

A análise propõe-se a responder as seguintes dúvidas, que são concatenadas entre si. Em primeiro lugar, o mecanismo da cláusula democrática é suficiente e adequado para se assegurar a promoção da democracia em face das velhas (golpes militares) e das novas ameaças nas Américas? Seria um "velho remédio" não apropriado para os tempos atuais? E, se não for suficiente, a cláusula democrática seria, no limite, deletéria, pois pode auxiliar na narrativa de existência de uma "democracia" nacional e contribuir para impedir mudanças e fortalecimento dos direitos à participação política?

\subsection{AS VELHAS E NOVAS CRISES DA DEMOCRACIA NO SÉCULO XXI}

Há três modos pelos quais os presidentes eleitos na América Latina ${ }^{6}$ têm comumente seus mandatos interrompidos prematuramente, excluindo a prática de crime comum ou afastamento por morte, doença e incapacidade: (i) golpe militar, (ii) renúncia antecipada e (iii) julgamentos políticos (impeachment) pela prática de condutas de grave afronta a ordem jurídica.

A redemocratização na América Latina tornou o golpe militar raro, sendo exceções mais significativas as duas tentativas de golpe na Venezuela (1992 e 2002) e o autogolpe de Fujimori no Peru (1992) ${ }^{7}$. Para Perez-Liñan, com o fim da guerra fria e desgaste dos regimes militares da época na região, o padrão de instabilidade democrática na América Latina nas últimas décadas é visto no confronto entre os

\footnotetext{
${ }^{5}$ Quando pertinente, também será utilizada a comparação com a cláusula democrática do Mercosul Mercado Comum do Sul (Protocolos de Ushuaia I e Ushuaia II) e da UNASUL - União Sul-Americana de Nações.

6 Utiliza-se aqui o termo "América Latina" como referente ao agregado de países de fala espanhola, francesa ou portuguesa do México à Argentina. Sobre a origem do termo e seus usos, ver GOBAT, Michel. The Invention of Latin America: A Transnational History of Anti-Imperialism, Democracy, and Race. The American Historical Review, vol. 118(5), December 2013, pp. 1345-1375.

${ }^{7}$ MONTEIRO, Leonardo Valente. Os neogolpes e as interrupções de mandatos presidenciais na América Latina: os casos de Honduras, Paraguai e Brasil. Revista de Ciências Sociais, v.49, n. 1, p.55-97, mar./jun., 2018, pp. 55-97, em especial p. 56

Revista de Direitos Fundamentais \& Democracia, Curitiba, v. 25, n. 3, p. 5-31, set./dez. 2020
} 
presidentes eleitos e maioria parlamentares de oposição, em meio a mobilizações populares e crise econômica ${ }^{8}$.

Com a exceção da ruptura por meio de golpe militar "clássico" em Honduras (2009; com uso até de carta de renúncia falsificada, como se verá abaixo) em 2009, a região enfrenta o paradoxo de ter regimes democráticos estáveis com governos instáveis ${ }^{9}$. Por isso, a hipótese de interrupção do mandato presidencial por meio do impeachment tem chamado a atenção da doutrina, pois há sugestões do uso do julgamento político como sucedâneo da "moção de censura" ou "desconfiança", típicas do regime parlamentarista, contrariando a soberania popular e o direito à participação política $^{10}$.

Entre as dúvidas jurídicas que surgem desses processos políticos, destaco as seguintes.

Se o processo de impeachment não for baseado em fatos graves ou não for pautado pelo devido processo legal, há violação do direito à democracia? $A$ impopularidade do presidente eleito e manifestações frequentes (panelaços, marchas, protestos etc.) justifica um processo político sem fundamento ou é impossível concluir que manifestações de rua devem ter peso maior que os votos da última eleição? Cabe ao direito internacional regular tais processos de impeachment ou tais situações só podem ser resolvidas nacionalmente, sob pena de violação do direito à participação política dos inconformados com a continuidade no poder do mandatário impopular?

\section{O SISTEMA INTERAMERICANO DE DIREITOS HUMANOS E A PROTEÇÃO}

\section{DA DEMOCRACIA}

\subsection{OS PROCESSOS INTERNACIONAIS DE DIREITOS HUMANOS}

O Direito Internacional dos Direitos Humanos é composto por duas partes indissociáveis: o rol de direitos de um lado e os processos internacionais que interpretam o conteúdo desses direitos e zelam para que os Estados cumpram suas

\footnotetext{
8 PÉREZ-LIÑAN, Aníbal. Presidential Impeachment and the New Political Instability in Latin America. Cambridge, New York: Cambridge University Press, 2007, p.3

9 COELHO, André. Inestabilidad política y caídas presidenciales en Sudamérica: causas y consecuencias. Revista de Ciência Política, Vol. 50, n 1, 2012, pp. 167-194, em especial p. 169.

10 Pérez-Liñan traz tabela sobre as variações entre as regras de julgamento político (impeachment) e usadas nos Estados da região (incluindo Estados Unidos). PÉREZ-LIÑÁN, Aníbal. Presidential impeachment and the new political instability in Latin America. Cambridge: Cambridge University Press, 2007, pp.140-141.
}

Revista de Direitos Fundamentais \& Democracia, Curitiba, v. 25, n. 3, p. 5-31, set./dez. 2020 
obrigações ${ }^{11}$.

Os processos internacionais de direitos humanos consistem em normas internacionais organizadas em diplomas normativos gerais ou específicos que analisam a situação de direitos humanos em um determinado Estado e, eventualmente, detectam a violação de direitos humanos bem como fixam reparações cabíveis ou impõe sanções. Os processos podem ser classificados pela origem (unilateral ou coletivo); natureza (política ou judiciária); finalidades (emitindo recomendações ou deliberações vinculantes); sujeição passiva (Estado ou indivíduo) e, finalmente, âmbito geográfico de atuação (global ou regional) ${ }^{12}$.

O processo (ou mecanismo) político é aquele que constata a existência de uma violação de direitos humanos a partir de uma apreciação de cunho político de um Estado ou de um conjunto de Estados. O processo (ou mecanismo) político pode ser unilateral ou mesmo coletivo, como se vê na apreciação de violação de direitos humanos no Conselho de Segurança, no Mecanismo de Revisão Periódica do Conselho de Direitos Humanos ou mesmo na Organização dos Estados Americanos (por exemplo, na crise de Honduras de 2009), que será aqui estudado ${ }^{13}$.

A defesa da democracia por meio de tais processos possui seus limites e condicionantes. O processo internacional político é tido como parcial, pois depende da avaliação discricionária e das injunções de momento, que podem acelerar seu uso ou paralisá-lo, a depender do país e da situação. Já o processo internacional judiciário é tido como imparcial, mas o devido processo legal do seu trâmite pode gerar uma proteção lenta e tardia ou até mesmo inexistente.

\subsection{AS QUATRO FACETAS DA PROMOÇÃO DA DEMOCRACIA PELO DIREITO} INTERNACIONAL DOS DIREITOS HUMANOS

A promoção da democracia por órgãos internacionais de direitos humanos possui, em geral, quatro facetas. Em primeiro lugar, há a defesa do regime democrático contra golpes e contra ditaduras. Em segundo lugar, há a fiscalização do funcionamento normal da democracia, com o monitoramento da realização das eleições, gerando

\footnotetext{
11 CARVALHO RAMOS, André de. Teoria geral dos direitos humanos na ordem internacional. 7a ed., São Paulo: Saraiva, 2019, em especial p. 352.

12 CARVALHO RAMOS, André de. Processo internacional de direitos humanos. $6^{a}$ ed, São Paulo: Saraiva, 2019, em especial p. 34.

13 CARVALHO RAMOS, André de. Processo internacional de direitos humanos. $6^{\mathrm{a}}$ ed, São Paulo: Saraiva, 2019, em especial p. 35.

Revista de Direitos Fundamentais \& Democracia, Curitiba, v. 25, n. 3, p. 5-31, set./dez. 2020
} 
credibilidade e legitimidade aos que forem eleitos. Em terceiro lugar, há a defesa do aprimoramento da democracia, para que esta supere barreiras à efetiva representatividade política, zelando por regras eleitorais transparentes, igualitárias e que evitem abusos de poder (econômico, político e dos meios de comunicação). Em quarto lugar, a defesa da democracia também exige que esses órgãos busquem a crítica a decisões majoritárias que representem violações de direitos de vulneráveis.

Todas essas espécies são realizadas, em algum grau, pelo chamado sistema interamericano de direitos humanos, que engloba essencialmente quatro diplomas normativos de suma importância ${ }^{14}$ : a Carta da Organização dos Estados Americanos (OEA), a Declaração Americana dos Direitos e Deveres do Homem, a Convenção Americana de Direitos Humanos e finalmente o Protocolo de San Salvador, relativo aos direitos sociais e econômicos.

Esses diplomas forjaram dois sistemas de proteção, que interagem de modo expresso. O primeiro sistema é o da Organização dos Estados Americanos (OEA), que utiliza os preceitos primários da Carta de criação da própria OEA e a Declaração Americana dos Direitos e Deveres do Homem. O segundo é o sistema da Convenção Americana de Direitos Humanos, criado no bojo da própria OEA, que não será aqui estudado $^{15}$.

\section{O SISTEMA DA CARTA DA OEA E A (VELHA) DEFESA DA DEMOCRACIA}

\subsection{ASPECTOS GERAIS: A LENTA CONSAGRAÇÃO DA "OEA DEMOCRÁTICA"}

Após a independência das antigas colônias espanholas, o sonho do Libertador Simon Bolívar era mimetizar a experiência norte-americana e criar uma grande federação de países recém-independentes na América Latina, em especial no norte da

14 Há outros tratados que também compõem a proteção de direitos humanos nas Américas, a saber: o Protocolo à Convenção Americana sobre Direitos Humanos Referente à Abolição da Pena de Morte, a Convenção Interamericana para Prevenir e Punir a Tortura, a Convenção Interamericana sobre o Desaparecimento Forçado de Pessoas, e a Convenção Interamericana para Prevenir, Punir e Erradicar a Violência contra a Mulher.

$15 \mathrm{Na}$ realidade, temos dois círculos concêntricos: um círculo amplo composto pelo sistema da Carta da OEA, com 35 Estados dessa Organização; um círculo menor, composto por 23 Estados, que ratificaram a Convenção Americana de Direitos Humanos (CADH) Então, os dois sistemas comungam, na essência, da mesma origem, a OEA. A diferença está no compromisso mais denso firmado pelos integrantes do segundo sistema, que conta inclusive com um tribunal especializado em direitos humanos, a Corte Interamericana de Direitos Humanos.

Revista de Direitos Fundamentais \& Democracia, Curitiba, v. 25, n. 3, p. 5-31, set./dez. 2020 
América do Sul (a República da Grande Colômbia) e com certa reserva em relação à Monarquia escravagista brasileira ${ }^{16}$.

Após o fracasso do sonho bolivariano, surge o pan-americanismo, movimento incentivado pelos Estados Unidos no final do século XIX e que visava à cooperação entre os Estados americanos, na linha da Doutrina Monroe ${ }^{17}$. Para dar forma a essa cooperação, foram organizadas conferências pan-americanas, que somaram nove grandes encontros do século XIX até a criação da Organização dos Estados Americanos em 1948. A institucionalização era rarefeita, tendo sido criado um Escritório Comercial das Repúblicas Americanas com sede em Washington para mero apoio administrativo. No plano político, as Conferências serviram para aproximação entre os Estados americanos, o que facilitou a criação, em 1948, justamente na Nona Conferência Pan-americana, da Organização dos Estados Americanos (OEA).

A guerra fria explica a criação de uma OEA com objetivos amplos, cujo tratado de criação espelhou os da Organização das Nações Unidas (ONU, criada em 1945). Os trabalhos ocorreram entre março e maio de 1948, convivendo com a guerra fria e fazendo nascer um tratado extenso com 112 artigos, assinado pelos 21 Estados fundadores da OEA, conhecido também como Carta de Bogotá ${ }^{18}$.

De acordo com a Carta de 1948, a OEA é uma organização intergovernamental, aberta a todos os Estados americanos, que acabaram - todos - ingressando na organização ao longo dos anos. Seus objetivos são amplos: garantia da paz e segurança internacionais, cooperação e ação solidária, promoção da democracia representativa, promoção dos direitos humanos e erradicação da pobreza, desenvolvimento econômico e social e prevenção de conflitos e busca de solução pacífica de controvérsias.

No que tange aos direitos humanos, a Carta está repleta de menções genéricas

${ }^{16}$ BOLÍVAR, Simón. Contestación de un americano meridional a un caballero de esta isla (1815) in BOLÍVAR, Simón. Doctrina del Libertador. Caracas: Fundación Biblioteca Ayacucho, 2009, pp. 18-87.

17 A "Doutrina Monroe" foi expressa em passagem de mensagem presidencial de 2 de dezembro de 1823 ao Congresso norte-americano e se encontra disponível em https://avalon.law.yale.edu/19th century/monroe.asp. Acesso em 30-06-2020.

18 São fundadores: Argentina, Bolívia, Brasil, Chile, Colômbia, Costa Rica, Equador, El Salvador, Estados Unidos da América, Guatemala, Haiti, Honduras, México, Nicarágua, Panamá, Paraguai, Peru, República Dominicana, Uruguai, Venezuela. Cuba é também membro fundador, porém, na VIII Reunião de Consulta de Ministros das Relações Exteriores em 1962, por pressão dos EUA, o governo comunista de Cuba foi suspenso de seus direitos de participar da OEA. Em 2009 essa resolução de suspensão foi revogada. Depois de 1948 ingressaram na OEA: Antígua e Barbuda (1967), Barbados (1967), Trinidad e Tobago (1967), Jamaica (1969), Grenada (1975), Suriname (1977), Dominica (1979), Santa Lucia (1979), São Vicente e Granadinas (1981), Bahamas (1982), Saint Kitts e Nevis (1984), Canadá (1990), Belize (1991) e Guiana (1991), totalizando 35 membros. Conferir em HERZ, Mônica. "Carta da OEA (1948)", in MAGNOLI, Demétrio. A história da paz, São Paulo: Contexto, 2008, p. 331-353.

Revista de Direitos Fundamentais \& Democracia, Curitiba, v. 25, n. 3, p. 5-31, set./dez. 2020 
de respeito aos direitos humanos, que consta já do Preâmbulo ${ }^{19} \mathrm{e}$, entre outros, dos artigos 3으, alínea "l"20, entre outros. Para especificar o rol de direitos, adotou-se, na própria Conferência de Bogotá em 1948, uma "Declaração" não vinculante ${ }^{21}$, denominada Declaração Americana de Direitos e Deveres do Homem.

No que tange à promoção da democracia, a Carta da OEA prevê, como um de seus objetivos, a promoção da democracia representativa "respeitado o princípio da não intervenção" (art. 2º , "b"22), o que sugere um tom soberanista e cauteloso da organização na temática.

Na prática, a OEA enfrentou as contradições políticas da região, na qual o Estado democrático e de maior peso na região - os Estados Unidos - conspiraram notoriamente a favor de ditaduras submissas aos seus interesses na América Latina, mesmo antes de 1948. Os apoios ao golpe militar na Guatemala (cujo Presidente Jacobo Arbenz havia promovido uma reforma agrária) em 1954, no Brasil em 1964, no Chile em 1973, entre outros, sem contar o apoio a ditaduras longevas, como a de Trujillo na República Dominicana ou a de Somoza na Nicarágua (desde os anos 30), dificultaram a adoção de uma posição firme da OEA contra regimes não democráticos e suas violações brutais de direitos humanos no continente ${ }^{23}$.

Foi a partir de 1991 que a promoção de direitos humanos foi alavancada por um fato inédito na história da OEA: pela primeira vez, todos os Estados membros efetivos (o governo de Cuba estava suspenso) eram democracias. Nesse ambiente, foi editado o Protocolo de Washington (1992), que introduziu a cláusula democrática na Organização (artigo 9ㅇ), pela qual um membro da OEA pode ser suspenso como sanção à ruptura do regime democrático.

19 In verbis: "Certos de que o verdadeiro sentido da solidariedade americana e da boa vizinhança não pode ser outro senão o de consolidar neste Continente, dentro do quadro das instituições democráticas, um regime de liberdade individual e de justiça social, fundado no respeito dos direitos essenciais do Homem".

20 In verbis: "Artigo 3ㅇ- Os Estados americanos reafirmam os seguintes princípios: (...) - I) Os Estados americanos proclamam os direitos fundamentais da pessoa humana, sem fazer distinção de raça, nacionalidade, credo ou sexo".

21 Posteriormente, a Corte Interamericana de Direitos Humanos decidiu que a Declaração Americana é interpretação autêntica das previsões genéricas sobre direitos humanos da Carta da OEA, possuindo força vinculante indireta. Ver mais em CARVALHO RAMOS, André de. Curso de direitos humanos. $7^{\text {a }}$ ed., São Paulo: Saraiva, 2020, p. 330.

${ }^{22}$ Artigo $2^{\circ}$ - Para realizar os princípios em que se baseia e para cumprir com suas obrigações regionais, de acordo com a Carta das Nações Unidas, a Organização dos Estados Americanos estabelece como propósitos essenciais os seguintes: (...) b. Promover e consolidar a democracia representativa, respeitado o princípio da não intervenção."

${ }^{23}$ Sobre as longevas ditaduras latino-americanas e a política norte-americana (mesmo anterior à Guerra Fria, como se viu na ascensão de Somoza nos anos 30 na Nicarágua) ver VANDEN, Harry E. e PREVOST, Gary. Politics of Latin America - The power game. New York/Oxford : Oxford University Press, 2002. 
Tendo em vista os dispositivos da Carta da OEA e da Declaração Americana de Direitos e Deveres do Homem é justo concluir que a proteção de direitos humanos esteve sempre no centro das preocupações formais dessa organização. Todavia, a evolução na implementação desses objetivos postos no papel foi lenta, com grande benevolência para com várias ditaduras ao longo das décadas.

Buscando romper com essa tradição de permissividade com ditaduras, a OEA optou por estruturar um processo internacional de direitos humanos coletivo político, capitaneado pela Assembleia Geral, pelo Conselho Permanente e pela Reunião de Consulta dos Ministros das Relações Exteriores.

3.2 O TÍMIDO MECANISMO POLÍTICO: A CLÁUSULA DEMOCRÁTICA E A CARTA DEMOCRÁTICA INTERAMERICANA

A cláusula democrática da OEA foi introduzida pelo Protocolo de Washington (1992), dando-se nova redação do artigo 9o da Carta, a qual permite suspender, por decisão da Assembleia Geral e por maioria qualificada de dois terços, qualquer Estado membro cujo governo tenha sido "deposto pela força". Trata-se de resposta interamericana ao "golpe militar clássico", típico do passado de vários países da região, com o uso da "sanção de não participação". Registre-se a timidez na resposta da OEA, pois não houve qualquer previsão formal de imposição de sanções coletivas econômicas ou outras medidas.

A suspensão atinge o exercício do direito de participação nas sessões da Assembleia Geral, da Reunião de Consulta, dos Conselhos da Organização e das Conferências Especializadas, bem como das comissões, grupos de trabalho e demais órgãos que tenham sido criados.

A faculdade de suspensão somente será exercida quando tenham sido infrutíferas as gestões diplomáticas que a Organização houver empreendido a fim de propiciar o restabelecimento da democracia no Estado afetado, que, mesmo suspenso, deverá continuar observando o cumprimento de suas obrigações com a Organização. A Assembleia Geral encerrará a suspensão mediante decisão adotada também por dois terços dos Estados-membros.

Em 2001, foi dado mais um passo rumo ao fortalecimento do mecanismo coletivo político de proteção de direitos humanos na OEA, com a aprovação da Carta Democrática Interamericana (CDI), em 11 de setembro de 2001. A Carta, por ter sido 
aprovada como resolução da Assembleia Geral, não é vinculante, compondo a soft law primária (direito em formação) que rege a temática na região, sendo importante vetor de interpretação de como promover a democracia prevista na Carta da OEA.

O ineditismo da Carta Democrática Interamericana consiste em seu objetivo de exigir o respeito à democracia formal (rotatividade do poder e eleições periódicas) e também à democracia substancial (justiça social), estabelecendo o direito à democracia, bem como superando a antiga preocupação de defesa da ordem democrática somente nos casos de "golpes de Estado" clássicos que caracterizaram a região por décadas.

A Carta possui 28 artigos divididos em 6 partes: I) a democracia e o sistema interamericano; II) a democracia e os direitos; III) democracia, desenvolvimento integral e combate à pobreza; IV) fortalecimento e preservação da institucionalidade democrática; V) a democracia e as missões de observação eleitoral; e VI) promoção da cultura democrática.

A manutenção das instituições democráticas é o foco da Parte IV da Carta Democrática Interamericana, com certa repetição dos comandos do Protocolo de Washington (incorporados na Carta da OEA). Estabelece-se que, caso se considere que o processo político democrático ou o seu exercício estão em risco, o SecretárioGeral ou o Conselho Permanente podem, com o consentimento prévio do governo afetado, realizar visitas e elaborar relatórios de avaliação coletiva da situação para instruir o Conselho Permanente sobre a necessidade de adotar medidas para preservar e consolidar a democracia na região (artigos 17 e 18 da CDI). Tal prerrogativa do Conselho Permanente de atuação para a normalização da institucionalidade democrática também pode ser provocada pelos Estados membros (artigo 20 da CDI).

A CDI prevê, também a suspensão do Estado, no caso de ruptura da ordem democrática ou "alteração constitucional que a afete gravemente", com a revogação da sanção somente após o retorno à normalidade. Note-se que já se pressente a necessidade de proteger a democracia contra as rupturas disfarçadas de reformas constitucionais.

Faltaram, contudo, mecanismos de acompanhamento do cumprimento, pelos Estados, dessas regras. Somente a ruptura do regime democrático (por meio do golpe de Estado ou "alteração constitucional que afete gravemente a democracia") possui uma sanção clara, que é a suspensão da participação na OEA, repetindo o disposto no 
Protocolo de Washington. As demais disposições são carentes de supervisão e, principalmente, cobrança dos Estados faltosos no ambiente do mecanismo político da Carta da OEA.

A questão que se coloca é saber como o mecanismo político funciona tanto no que tange aos casos clássicos e indisputados de golpes de Estado quanto em relação a casos nos quais há uso de instrumentos constitucionais de interrupção do mandato presidencial em um ambiente de disputa de narrativas entre oposição e situação.

Por isso, três casos serão aqui analisados: o caso do Presidente Zelaya (Honduras, 2009), o caso do Presidente Lugo (Paraguai, 2012) e o caso da Presidente Rousseff (Brasil, 2016) e as diferentes reações da OEA no uso da "cláusula democrática" e da CDI, comparando, brevemente com a reação de outras organizações internacionais, em especial o Mercosul (Mercado Comum do Sul) e a Unasul (União Sul-Americana de Nações).

\section{O VELHO NAS CRISES DA DEMOCRACIA DA AMÉRICA LATINA: O GOLPE DE ESTADO EM HONDURAS}

A história latino-americana está repleta de golpes de Estado e interrupção, pela força, do mandato de governantes eleitos, como se vê na história recente brasileira, com o golpe militar de 1964. A ruptura da democracia é, então, uma velha ameaça em face da qual o sistema interamericano de direitos humanos preparou-se especificamente para enfrentar, como se viu na aprovação da cláusula democrática do Protocolo de Washington de 1992.

O maior teste do enfrentamento a esse tipo de ruptura democrática nos últimos anos ocorreu em Honduras, em 200924. Após meses de disputas entre o Presidente José Manuel Zelaya Rosales e o Poder Legislativo e Judiciário, tropas do Exército ingressaram na residência presidencial, de madrugada, no dia 28 de junho de 2009, prenderam e conduziram o Presidente Zelaya para ser imediatamente enviado em avião militar para a Costa Rica. No mesmo dia, o Congresso hondurenho reuniu-se, tendo ocorrido a leitura de uma falsa carta de renúncia ${ }^{25}$. Assumiu o poder o senhor

\footnotetext{
${ }^{24}$ Apesar da deposição do Presidente Mahuad do Equador, em janeiro de 2000, ter ocorrido após levante indígena com apoio de parte das Forças Armadas, liderada pelo Coronel Lucio Gutierrez, como visto acima. OEA, Comissão Interamericana de Direitos Humanos, Relatório sobre o Equador, 2000. Disponível em http://www.cidh.oas.org/annualrep/99eng/Chapter4a.htm, acesso em 13-07-2020.

25 HONDURAS, Informe de la Comisión de la Verdad y la Reconciliación (CVR). Para que los hechos no se repitan: Informe de la Comisión de la Verdad y la Reconciliación, julho de 2011, em especial pp. 146. Revista de Direitos Fundamentais \& Democracia, Curitiba, v. 25, n. 3, p. 5-31, set./dez. 2020
} 
Roberto Micheletti Baín, que utilizou tropas do Exército e forças policiais para dispersar manifestantes, causando pelo menos 7 mortes, implantando o estado de exceção e toque de recolher. Houve também a detenção de número incerto de pessoas ${ }^{26}$.

Foi utilizado, pela primeira vez, o art. $9^{\circ}$ da Carta da OEA combinado com o art. 21 da CDI: a Assembleia Geral da OEA suspendeu Honduras, em 04 de julho de 2009, do exercício do direito de participação na organização ${ }^{27}$.

Após negociações (denominado de "Diálogo Guaymuras - Acordo Tegucigalpa San José) intermediadas pela ex-Presidente da Costa Rica, Óscar Arias, foi criada uma "Comissão da Verdade e Reconciliação" para esclarecer os fatos e sugerir recomendações para fortalecer a institucionalidade democrática, prevenindo a ocorrência de novos golpes militares no país.

No referido acordo, foi também acordada a volta ao poder do Presidente de jure Zelaya, o que não foi cumprido pelo governo de facto e novas eleições foram realizadas em novembro de 2009, ainda sob o regime golpista.

Em janeiro de 2010, assumiu o novo Presidente, Sr. Porfírio Lobo. Somente em maio de 2011, sob a mediação da Colômbia e Venezuela, foi celebrado um "acordo de reconciliação nacional e consolidação do sistema democrático em Honduras", entre Zelaya e Porfírio Lobo, reunindo uma série de medidas para garantir a segurança do ex-Presidente e também para assegurar o cumprimento da Constituição ${ }^{28}$. Logo após, em junho de 2011, a suspensão de Honduras foi revogada pela Assembleia Geral da $\mathrm{OEA}^{29}$.

Esse relato foi importante para demonstrar certa insuficiência da mera suspensão do direito de participação: o governo de facto impôs sua vontade e somente em 2011 foi celebrado acordo, que, obviamente, não restituiu o tempo de governo interrompido pelo golpe militar.

Disponível em https://www.oas.org/es/sap/docs/DSDME/2011/CVR/HondurasInformeCVR_TOMO1.pdf, acesso em 13-07-2020.

26 ORGANIZAÇÃO DOS ESTADOS AMERICANOS, Comissão Interamericana de Direitos Humanos, Honduras: Derechos Humanos y Golpe de Estado. OEA/Ser.L/V/II. Doc 55, 2009, em especial parágrafo 98 e 99. Disponível em http://www.cidh.org/countryrep/Honduras09sp/Indice.htm, acesso em 13-072020.

27 ORGANIZAÇÃO DOS ESTADOS AMERICANOS, OEA/Ser.P AG/RES 1 (XXXVII-E/09), de 4 de julho de 2009. Disponível em: http://www.oas.org/consejo/sp/AG/37SGA.asp\#inf , acesso em 13-07-2020.

28 "Acuerdo para la Reconciliación Nacional y la Consolidación del Sistema Democrático en la República de Honduras" ou "Acuerdo de Cartagena". Colombia, 22 de maio de 2011. Disponível em: http://wsp.presidencia.gov.co/Prensa/2011/Mayo/Paginas/20110522_02.aspx, acesso em 13-07-2020.

29 ORGANIZAÇÃO DOS ESTADOS AMERICANOS, Resolução da Assembleia Geral da OEA sobre a participação de Honduras na OEA, AG/RES.1(XLI-E/11), 22 de junho de 2011. Disponível em: http://www.oas.org/council/sp/AG/41SGA.asp, acesso em 13-07-2020.

Revista de Direitos Fundamentais \& Democracia, Curitiba, v. 25, n. 3, p. 5-31, set./dez. 2020 


\section{O NOVO NAS CRISES DA DEMOCRACIA: O PROCESSO DE} IMPEACHMENT E SEU IMPASSE

Um segundo tipo de crise vivenciado pelas democracias latino-americanas no séc. XXI é o uso de julgamentos políticos - ou parlamentares - para interromper mandatos presidenciais, com base em avaliações discricionárias realizadas pelo Poder Legislativo, por intermédio do instituto de origem estadunidense do impedimento (impeachment).

Não se trata de julgamento por delito criminal (a ser realizado pelo Poder Judiciário), mas sim uma avaliação política sobre a existência de infração à ordem jurídica de tal gravidade que merece a sanção de interrupção do mandato (entre outras possíveis).

Em regimes presidencialistas, o impedimento passou por uma recente adaptação na América Latina, servindo como modo de interrupção de mandatos de Presidentes impopulares, com frágil apoio parlamentar em ambientes de crise econômica e escândalos repercutidos fortemente na mídia. Trata-se de sucedâneo impróprio de uma espécie de "moção de censura" (ou moção de desconfiança) típica dos regimes parlamentarista. No espectro do "julgamento político" é possível uma condenação sem que tenha existido qualquer infração real por parte do governante impopular, sendo o voto de cada parlamentar absolutamente discricionário, sem exigência de fundamentação.

Kasahara e Marsteintredet distinguem três aspectos decisivos sobre o uso do julgamento político como forma de interrupção do mandato presidencial. O primeiro diz respeito à definição das condutas comissivas ou omissivas que podem dar início a um juízo político. O exemplo brasileiro mostra que há junção de condutas vagas ("quebra do decoro") com lista detalhadas de atos presidenciais consubstanciando o "crime de responsabilidade") da Lei n. 1079/50. O segundo aspecto trata da definição do órgão responsável pelo julgamento político, sendo o mais comum na região que há monopólio do Poder Legislativo. E o terceiro aspecto diz respeito ao quórum para a abertura do processo e também para a condenação, sendo o mais comum é um quórum qualificado, o que difere o julgamento político da moção de desconfiança que, em geral, exige somente maioria simples nos regimes parlamentaristas ${ }^{30}$.

30 KASAHARA, Yuri e MARSTEINTREDET, Leiv. Presidencialismo em crise ou parlamentarismo por outros meios? Impeachments presidenciais no Brasil e na América Latina. Revista de Ciências Sociais, , v.49, n. 1, , mar./jun., 2018, pp.30-54, em especial pp.38-39.

Revista de Direitos Fundamentais \& Democracia, Curitiba, v. 25, n. 3, p. 5-31, set./dez. 2020 
No que tange ao direito à democracia e ao devido processo legal, essas características formais do processo de impeachment geram um impasse.

De um lado, há um formalismo procedimental, com uma acusação (com fatos e fundamentos jurídicos), ampla defesa e contraditório, com eventual recurso ao Poder Judiciário questionando um ato ou uma etapa procedimental.

De outro, há uma deliberação sem qualquer fundamentação (ou com fundamentação suicida - reconhece que não houve crime de responsabilidade, mas vota a favor pela ausência de condições de governabilidade) por parte dos membros do Poder Legislativo, a despeito do formato jurídico do julgamento.

Para os críticos, como se trata de utilização imprópria do instituto do impeachment, é denominado "golpe branco31", "neogolpismo"32, "golpe jurídicoparlamentar" ou "golpe parlamentar"33, pois ofenderia a soberania popular e implantaria um "parlamentarismo de facto" sem base constitucional.

Em outra forma de classificação, Heine e Weiffen separam as novas crises democráticas da região em duas espécies: as exógenas e as endógenas. As crises exógenas seriam extra-institucionais, ocasionadas por protestos de massa e renúncias forçadas. O maior exemplo seria o caso De la Rúa na Argentina em 2001. Já as crises endógenas seriam aquelas nas quais há conflito entre os Poderes, sendo utilizado o julgamento político como forma de interrupção do mandato presidencial, com vitória da maioria oposicionista no Poder Legislativo ${ }^{34}$.

$\mathrm{Na}$ realidade, é difícil a separação entre a crise exógena e a endógena, pois ainda não há registro de interrupção do mandato de presidente eleito com alta taxas de popularidade e em um ambiente de crescimento econômico. Assim, para que uma crise endógena gere a interrupção do mandato presidencial é necessária uma crise exógena.

Contudo, não há automatismo. É possível que uma crise exógena nada mude,

31 PRONER, Carol. Golpe branco no Brasil. in PRONER, Carol; CITTADINO, Gisele; NEUENSCHWANDER, Juliana; PEIXOTO, Katarina e GUIMARÃES, Marília Carvalho (orgs). A resistência internacional ao golpe de 2016. Bauru/SP: Canal Editora, 2016, pp. 155-159.

32 ARAUJO, Matheus Alexandre e PEREIRA, Vanessa dos Santos. Rupturas, neogolpismo e América Latina: uma análise sobre Honduras, Paraguai e Brasil. Revista Katálysis, v. 21, n. 1, , jan./abr. 2018, pp. 125-136. SOLER, Lorena e PREGO, Florencia. Derechas y neogolpismo en América Latina. Una lectura comparada de Honduras (2009), Paraguay (2012) y Brasil (2016). Historia y problemas del siglo XX , Año 10, Volumen 11, julio-diciembre de 2019, pp. 33-52.

33 Monteiro denominou a situação do caso Lugo de "golpe parlamentar relâmpago " e a do caso Dilma Rousseff de "neogolpe jurídico-parlamentar". MONTEIRO, Leonardo Valente. Os neogolpes e as interrupções de mandatos presidenciais na América Latina: os casos de Honduras, Paraguai e Brasil. Revista de Ciências Sociais, v.49, n. 1, p.55-97, mar./jun., 2018, pp. 55-97, em especial p. 76 e p. 80 ${ }^{34} \mathrm{HEINE}$, Jorge e WEIFFEN, Brigitte. 21st Century Democracy Promotion in the Americas - standing up for the polity. New York: Routledge, 2015, em especial pp. 89-92.

Revista de Direitos Fundamentais \& Democracia, Curitiba, v. 25, n. 3, p. 5-31, set./dez. 2020 
com o governo impopular controlando a maioria parlamentar. Mas também é possível que uma crise endógena gere uma crise exógena, com o Poder Legislativo aprovando (ou rejeitando) diversas medidas para inviabilizar a ação do Poder Executivo, evitando uma retomada econômica ou criando uma agenda negativa (aquilo que a mídia brasileira chama de "pauta bomba"), o que resultará, assim, uma crise exógena com protestos e manifestações contra a "inépcia" do Poder Executivo em administrar o país.

Dois casos de crises endógenas ficaram célebres na região: o impeachment do Presidente Fernando Lugo (Paraguai) e o da Presidente Dilma Rousseff (Brasil), que serão aqui analisados.

\subsection{O CASO LUGO}

Em junho de 2012, houve a abertura do julgamento político para interrupção do mandato do Presidente Fernando Lugo Méndez do Paraguai. Consta do libelo acusatório os seguintes fatos: 1) conivência com atos políticos no comando de engenharia das forças armadas; 2) instigação e facilitação de invasões de terras na zona da Nacunday; 3) incapacidade de reduzir a insegurança pública e combater eficazmente o "Exército do Povo Paraguaio" (grupo que realizou diversos atentados em oposição ao governo); 4) assinatura do Protocolo de Ushuaia II do Mercosul, que seria uma ofensa à soberania do Paraguaia (ironicamente, o citado tratado "ofensivo à soberania" visa preservar a democracia dos Estados membros daquela organização) e 5) inépcia e desídia no Caso do "Massacre de Curuguaty", nome dado as mortes de 11 camponeses e 6 policiais durante o cumprimento de ordem de desocupação de terras públicas, dias antes do processo de impeachment ${ }^{35}$. Quanto às provas, o libelo acusatório alegou que todos os fatos seriam notórios (mesmo os que imputavam ações ao Presidente) e, consequentemente, "no necesitan ser probadas, conforme a nuestro ordenamiento jurídico vigente". Em síntese, a acusação imputava a Lugo ter "perjudicado enormemente los intereses supremos de la Nación"36.

O processo iniciado em 21 de junho de 2012 durou aproximadamente 30 horas no Paraguai, tendo sido acatado o afastamento do Presidente e o fim do seu mandato.

\footnotetext{
${ }^{35}$ Araújo e Pereira consideram o massacre o "estopim" para a abertura do processo de impeachment. ARAUJO, Matheus Alexandre e PEREIRA, Vanessa dos Santos. Rupturas, neogolpismo e América Latina: uma análise sobre Honduras, Paraguai e Brasil. Revista Katálysis, v. 21, n. 1, , jan./abr. 2018, pp. 125-136, em especial p. 130.

36 Libelo acusatório disponível em http://diplomatizzando.blogspot.com.br/2012/06/o-paraguai-e-oprotocolo-de-ushuaia-ii.html, acesso em 13-07-2020

Revista de Direitos Fundamentais \& Democracia, Curitiba, v. 25, n. 3, p. 5-31, set./dez. 2020
} 
A Sala Constitucional da Corte Suprema de Justiça do Paraguai não acatou o pedido do Presidente Lugo de considerar inconstitucional o processo, argumentando especialmente de se tratar de julgamento político de competência exclusiva do Congresso Nacional ${ }^{37}$. No plano internacional duas organizações internacionais UNASUL e MERCOSUL - acionaram suas respectivas "cláusulas democráticas" similares à da Carta da OEA, sendo o Paraguai suspenso de ambas as organizações ${ }^{38}$.

Na OEA, apesar de diversas sessões extraordinárias do Conselho Permanente, não houve nenhuma declaração oficial do órgão. O Secretário-Geral da OEA na época, o chileno José Miguel Insulza, chefiou missão in loco em de 01 a 03 de julho de 2012, cujo relatório não constatou ruptura do regime democrático, registrando, ao contrário, o compromisso de realização de eleições em 2013. Após a eleição de Horacio Cartes em 2013, houve a revogação das duas decisões de suspensão (Unasul e Mercosul).

\subsection{O CASO DILMA ROUSSEFF E A PROIBIÇÃO DO AGIR PARLAMENTAR} ARBITRÁRIO

O caso Dilma Rousseff refere-se a processo de impedimento da Presidente Dilma Rousseff (eleita para o mandato de 2015-2018) por prática de crime de responsabilidade ${ }^{39}$ consistente em violações repetidas à Lei de Responsabilidade Fiscal e à Lei Orçamentária Anual ${ }^{40}$. A denúncia foi considerada adequada para dar início a um processo de impedimento em 01 de dezembro de 2015 pelo então Presidente da Câmara dos Deputados ${ }^{41}$, tendo sido aprovada a instauração do

37 PARAGUAI. Decisión provisional de la acción de inconstitucionalidad $n$. 1533. Disponível em http://www.pj.gov.py/descargas/ID1-317_accion_de_inconstitucionalidad.pdf, acesso em 13-07-2020 38 Protocolo Adicional sobre Democracia (2010) no âmbito da Unasul. Decisión n 26/12. Disponível: http://www.itamaraty.gov.br/images/ed_integracao/docs_UNASUL/DEC26.2012.pdf. Ver mais sobre a cláusula democrática do Mercosul em CARVALHO RAMOS, André de. Derechos Humanos y el Mecanismo Híbrido del Mercosur: ¿Cómo Controlar la Aplicación de la cláusula democrática? Revista de la secretaria del Tribunal permanente de revisión. Año 3, no 6; agosto 2015, pp. 48-68. Sobre a reação do Mercosul e da Unasul contra a deposição do Presidente Lugo ver também ALMEIDA, Wilson e SANTANA, Hadassah Laís. Integração e democracia: os interesses políticos locais que distorcem o direito internacional e a crise política resultante da suspensão do Paraguai do Mercosul. Revista de Informação Legislativa. Ano 51, n. 203, jul/set. 2014, pp. 91-110.

39 Definido genericamente no art. 85 da Constituição de 1988 e regulamentado pela Lei n. 1.079/50.

40 Ver o texto integral das acusações que deram início ao processo de impeachment em https://congressoemfoco.uol.com.br/especial/noticias/a-integra-do-pedido-de-impeachment-de-dilmaapoiado-pela-oposicaol.

41 Poucos dias após a aceitação do pedido de início do trâmite, o Procurador-Geral da República Rodrigo Janot requereu o afastamento do Presidente da Câmara dos Deputados, então Dep. Federal Eduardo Cunha, que, à época, era investigado em inquéritos criminais no Supremo Tribunal Federal, fundado na reiteração de práticas criminosas e no uso do cargo para evitar esclarecimento sobre suas Revista de Direitos Fundamentais \& Democracia, Curitiba, v. 25, n. 3, p. 5-31, set./dez. 2020 
processo em 17 de abril de 2016 pela Câmara dos Deputados ${ }^{42}$ e determinado o afastamento em definitivo da Presidente Rousseff em 31 de agosto de 2016. Contudo, a inesperada decisão do Senado de cassar o mandato de Rousseff, mas preservar seus direitos políticos (o chamado "fatiamento"), aproximou o caso de uma moção de desconfiança ${ }^{43}$.

Apesar do intenso crivo sobre aspectos procedimentais, devido processo legal e alcance das sanções no processo de impedimento ${ }^{44}$, o Supremo Tribunal Federal não apreciou a existência do crime de responsabilidade e eventual desvio de finalidade no uso do impeachment como instrumento político de interrupção do mandato presidencial pela maioria parlamentar oposicionista.

A oportunidade para tal revisão de mérito ocorreu no Mandado de Segurança n. 34.193 dias antes do seu afastamento provisório, em maio de 2016, no qual a Presidente Dilma Rousseff expressamente apontou a existência de desvio de finalidade e inexistência de crime de responsabilidade, pleiteando a suspensão do processo de impeachment.

Contudo, a liminar foi indeferida pelo Relator Min. Teori Zavascki, para quem (i) seria difícil a prova da verdadeira finalidade de um ato parlamentar, que naturalmente dissimula seus reais motivos; (ii) o desvio de finalidade teria sido apoiado por quase 370 deputados, o que mostra que a atuação de parlamentares nesse tipo de julgamento não está dissociada do coeficiente político; (iii) há limites no mandado de segurança (exigência de direito líquido e certo) e prazo decadencial de 120 dias, que inviabilizam seu uso e (iv) o juiz constitucional sobre a ocorrência ou não dos fatos ou sobre a procedência ou não da acusação no impeachment é o Senado Federal

condutas. Contudo, o Supremo Tribunal Federal só o afastou em maio de 2016, semanas após o processo de impeachment ter findado na Câmara dos Deputados. BRASIL, Supremo Tribunal Federal, ACO n. 4.070/DF, Rel. Min. Teori Zavascki, referendo na ação cautelar, j. 5-5-2016, DJe de 21-10-2016.

${ }^{42}$ A CF/88 exige maioria de dois terços para tal decisão. O resultado final foi de 367 votos a favor da continuidade do processo de impeachment e 137 votos contra, com 7 abstenções. Dois deputados não votaram. Houve ainda a confirmação de tal decisão pelo Senado em 12 de maio de 2016 (após decisão do STF, exigindo tal deliberação), tendo sido obtidos 55 votos a favor do prosseguimento do processo e 22 contrários.

$43 \mathrm{O}$ resultado final no Senado Federal foi de 61 votos a favor do impeachment e 20 contrários. BRASIL. Senado Federal como órgão judiciário. Sentença. Disponível em:

https://www12.senado.leg.br/noticias/arquivos/2016/08/31/veja-a-sentenca-de-impeachment-contradilma-rousseff, acesso em 13-07-2020

${ }_{44}$ Vide, em especial, a Arguição de Descumprimento de Preceito Fundamental n. 378, que estabeleceu, por exemplo, que "(...) No curso do procedimento de impeachment, o acusado tem a prerrogativa de se manifestar, de um modo geral, após a acusação. Concretização da garantia constitucional do devido processo legal (due process of law)". BRASIL, Supremo Tribunal Federal ADPF 378 MC, rel. p/ o ac. min. Roberto Barroso, j. 16-12-2015, P, DJE de 8-3-2016.

Revista de Direitos Fundamentais \& Democracia, Curitiba, v. 25, n. 3, p. 5-31, set./dez. 2020 
(previamente autorizado pela Câmara dos Deputados). ${ }^{45} \mathrm{O}$ parecer do ProcuradorGeral da República, Rodrigo Janot, reiterou ainda a dificuldade de se provar desvio de finalidade em atos parlamentares de oposição política, pois o julgamento da Câmara dos Deputados é "eminentemente político, situação em que oposição política e desvio de finalidade se colocam em zona fronteiriça de difícil distinção"46.

Anos depois (final de 2018), o Min. Alexandre de Moraes decidiu pela denegação final do Mandado de Segurança n. 34.193 pela inexistência do "direito líquido e certo" tal qual apontado em 2016.

Contudo, houve sutil distanciamento da posição do primeiro Relator, Min. Teori Zavascki, por meio de expressa menção à possibilidade de revisão judicial em casos nos quais haja inconteste agir arbitrário dos parlamentares. Para o Min. Alexandre de Moraes, a análise da constitucionalidade da atuação em processo de impeachment por parte do STF abarca (i) a verificação da realidade dos fatos e (ii) a coerência lógica da decisão política discricionária com os fatos. Se ausente a coerência, há vício no agir político por ofensa ao "ao princípio da proibição da arbitrariedade dos poderes públicos que impede o extravasamento dos limites razoáveis da discricionariedade"47.

No plano interamericano, o Secretário-Geral da OEA, Luis Almagro, emitiu nota salientando a (i) natureza política do processo e (ii) que o presidencialismo latinoamericano não permitia medidas como "moção de desconfiança" como se fosse um sistema parlamentarista, concluindo que a soberania popular (que elegeu o presidente) não pode ser alterada por razões políticas oportunistas ${ }^{48}$. A UNASUL também emitiu nota no mesmo sentido ${ }^{49}$. Contudo, na OEA e no Mercosul não houve seguimento de apreciação do caso como ruptura do regime democrático para fins de suspensão da participação brasileira em tais organizações.

\footnotetext{
45 Consta do voto: "Admitir-se a possibilidade de controle judicial do mérito da deliberação do Legislativo pelo Poder Judiciário significaria transformar em letra morta o art. 86 da Constituição Federal, que atribui, não ao Supremo, mas ao Senado Federal, autorizado pela Câmara dos Deputados, a competência para julgar o Presidente da República nos crimes de responsabilidade. Por isso mesmo, é preciso compreender também que o julgamento, em tais casos, é feito por juízes investidos da condição de políticos, que produzem, nessa condição, votos imantados por visões de natureza política, que, consequentemente, podem eventualmente estar inspirados em valores ou motivações diferentes dos que seriam adotados por membros do Poder Judiciário". BRASIL, Mandado de Segurança n. 34.193-DF, decisão de 11 de maio de 2016, DJE n 97, divulgado em 12/05/2016.

${ }^{46}$ BRASIL, Mandado de Segurança n. 34.193-DF, Relator original Min. Teori Zavascki, Relator final Min. Alexandre de Moraes, parecer da PGR (custos legis) de 5 de setembro de 2016.

47 BRASIL, Mandado de Segurança n. 34.193-DF, Relator Min. Alexandre de Moraes, decisão de 7 de dezembro de 2018, DJE n² 266, divulgado em 11/12/2018.

48 OEA, Declaração do Secretário-Geral da OEA Luis Almagro após reunião com a Presidente Constitucional do Brasil Dilma Rousseff, em 15 de abril de 2016. Disponível em https://www.oas.org/pt/centro midia/nota imprensa.asp?sCodigo=P-044/16

$49 \mathrm{https}: / / w w w . o a s . o r g / e n / m e d i a ~ c e n t e r / p r e s s ~ r e l e a s e . a s p ? s C o d i g o=E-044 / 16$

Revista de Direitos Fundamentais \& Democracia, Curitiba, v. 25, n. 3, p. 5-31, set./dez. 2020
} 
$\mathrm{Na}$ OEA, apesar da nota crítica do Secretário-Geral, as irregularidades lá mencionadas sequer foram registradas nas atas do Conselho Permanente da OEA ${ }^{50}$. Na sessão de 7 de setembro de 2016 (ata somente aprovada em dezembro de 2019), houve manifestação solitária da Delegação brasileira (governo Temer) exaltando a conclusão do processo de impeachment, "sem ruptura ou sobressaltos", tendo sido seguido o "devido processo legal, estabelecido na Constituição Federal e em leis específicas" 51 .

\section{OS RISCOS DA INEFETIVIDADE DA CLÁUSULA DEMOCRÁTICA}

Pelas três referências empíricas vistas acima (Honduras, Paraguai e Brasil), o mecanismo político da OEA foi desencadeado com certa dose de efetividade somente no caso de golpe militar clássico (Honduras). Nas crises contemporâneas da democracia na região, o uso de instrumentos constitucionais para a interrupção do mandato presidencial não sofreu crivo do mecanismo da cláusula democrática.

A ausência de crivos nacional e internacional sobre o uso camuflado do processo de impeachment estimula a remoção de presidentes pelas maiorias parlamentares de oposição, criando uma receita composta por (i) "manifestações de ruas", aliada a (ii) campanhas mediáticas (repercutindo determinado escândalo) e (iii) ruína econômica (gerada pela incompetência do Poder Executivo ou acelerada pelo Poder Legislativo). Ou, como antídoto, impulsiona o presidencialismo de coalizão ou de alianças indesejadas pela maioria da população.

Cria-se um "parlamentarismo camuflado", o que atenta ainda mais contra a soberania popular em países como o Brasil, que já submeteu tal sistema de governo em duas ocasiões a aprovação popular (referendo, em 1963 e plebiscito em 1993) na fase republicana de sua história, tendo sido em ambos vitorioso o presidencialismo ${ }^{52}$.

50 GÓMEZ MARTíN, A. La destitución de Fernando Lugo y Dilma Rousseff. Una comparación de ambas crisis democráticas desde la labor de las organizaciones regionales. Revista Integración y Cooperación Internacional, n. ${ }^{\circ} 27$ dezembro de 2018. Disponível em http://rephip.unr.edu.ar/bitstream/handle/2133/13965/Art\%C3\%ADculo\%201\%20

$\% 20$ Revista\%20Nro.\%2027. pdf?sequence=3. Acesso em 13-07-2020.

51 ORGANIZAÇÃO DOS ESTADOS AMERICANOS, OEA/Ser.G CPIACTA 2088/16. Sessão de 7 de setembro de 2016. Disponível em http://www.oas.org/es/council/CP/documentation/minutes/. Acesso em 13-07-2020

52 BRASIL, Tribunal Superior Eleitoral, Resultado Geral do Referendo de 1963. Disponível em: justicaeleitoral.jus.br/arquivos/referendo-de-

1963/rybena_pdf?file=http://www.justicaeleitoral.jus.br/arquivos/referendo-de-1963/at_download/file. Acesso em 13-07-2020. BRASIL, Tribunal Superior Eleitoral, Resultado Geral do Plebiscito de 1993. Disponível 
Tal situação de desvalorização do voto majoritário nas eleições presidenciais aumenta o descrédito com a democracia, em especial se há mudança abrupta de programa de governo após o impeachment.

Além disso, o uso insincero do impeachment transforma esse instrumento em uma simulação de julgamento, no qual até mesmo a defesa da inexistência do fato grave pouco importa, como se viu nas declarações dos congressistas brasileiros em determinados momentos do processo de impeachment da Presidente Dilma Rousseff ${ }^{53}$ ou mesmo se há ou não espaço de instrução probatória e contraditório (como se viu no Caso Lugo, cujo julgamento político durou 30 horas).

Esse "jogo de cartas marcadas"54 põe em risco a credibilidade da democracia representativa, pois não se confia sequer nos motivos reais de uma interrupção do mandato presidencial. Além disso, corre-se o risco, como aponta Coelho, de se sedimentar um "modelo de ação política" para destituir presidentes eleitos ${ }^{55}$.

Tal situação de dilapidação da via democrática contraria a expectativa de PerezLiñan, para quem o fenômeno da instabilidade dos governos conviveria com a estabilidade democrática na região. $\mathrm{O}$ uso da gramática jurídica para interromper os mandatos presidenciais seria um sucedâneo legítimo aos tradicionais golpes militares na região, preservando-se a Constituição e a democracia ${ }^{56}$.

Contudo, tal uso camuflado e insincero do impeachment pode levar à desvalorização do próprio sistema democrática, uma vez que a eleição presidencial é, em geral, o espelho mais fiel da vontade popular por respeitar o "uma pessoa, um voto" e, em vários países, por exigir maioria absoluta dos eleitores.

O uso do impeachment para a deposição de governantes impopulares no presidencialismo resulta, com o tempo, na criação de uma "democracia de opinião"57,

1993/rybena pdf?file=http://www.justicaeleitoral.jus.br/arquivos/plebiscito-de-1993/at download/file.

Acesso em 13-07-2020.

53 Para o STF, ao menos durante o caso Dilma Rousseff, as opiniões manifestadas por parlamentares durante o julgamento político não servem como prova cabal de desvio de finalidade no uso do impeachment. Ver Mandado de Segurança n. 34.441, Relator min. Alexandre de Moraes, decisão monocrática de denegação da ordem de 7 de dezembro de 2018. Ver também ADPF 378 MC, Rel. Min. Edson Fachin, Redator p/ Acórdão: Min. Roberto Barroso, Tribunal Pleno, DJe de 8/3/2016.

${ }^{54}$ ARAUJO, Matheus Alexandre e PEREIRA, Vanessa dos Santos. Rupturas, neogolpismo e América Latina: uma análise sobre Honduras, Paraguai e Brasil. Revista Katálysis, v. 21, n. 1, , jan./abr. 2018, pp. 125-136, em especial p. 134.

55 SOUZA, André Luiz Coelho Farias de. Um Novo Modelo de Destituição de Mandatários ou a Releitura de Velhas Práticas? Reflexões sobre a instabilidade presidencial contemporânea na América Latina. Revista Brasileira de Estudos Políticos, n. 113, jul./dez. 2016, pp. 11-50, em especial p. 48

56 PÉREZ-LIÑÁN, Aníbal. Presidential impeachment and the new political instability in Latin America. Cambridge: Cambridge University Press, 2007, em especial p. 213

57 SCHOLLER, Heinrich. Os ajustes necessários da democracia representativa. in CLÈVE, Clèmerson Merlin; SARLET, Ingo W. e PAGLIARINI, Alexandre Coutinho. Direitos humanos e democracia. Rio de Revista de Direitos Fundamentais \& Democracia, Curitiba, v. 25, n. 3, p. 5-31, set./dez. 2020 
forjada pela mídia e redes sociais (com as conhecidas manipulações de "fake news", uso de perfis falsos, gatilhos eletrônicos -"robôs" etc), que, sem regras, pode buscar se emancipar da democracia formal. Em estudo recente, Mounk retratou a ascensão no pós-crise de 2008 de uma certa "democracia sem direitos", na qual populistas eleitos em diversos países afirmam serem a verdadeira "voz do povo" e acreditam que toda a resistência a seu governo é ilegítima, o que resulta, caso sejam bem sucedidos, em uma democracia iliberal, que, conclui o autor, pode degenerar em uma verdadeira ditadura ${ }^{58}$.

Ou, por um outro lado, a decepção com a democracia representativa, pode gerar a "democracia das ruas" ("'the people in action"), com grupos sociais excluídos buscando a implementação de suas agendas pela via da insurgência e manifestações de rua, dado o bloqueio e engessamento do sistema eleitoral. Para De la Torre, as limitações desse modelo como forma de democracia direta são claras: nem todos os grupos sociais excluídos se dispõem a ocupar as ruas e tal ocupação também não se dá de maneira geograficamente uniforme em determinado Estado ${ }^{59}$.

A prática da OEA sobre o uso da cláusula democrática demonstra uma interpretação restritiva da Carta Democrática Interamericana, deixando de aferir o respeito ao direito à democracia na hipótese de desrespeito à vontade popular ter ocorrido ao menos formalmente de acordo com as vias constitucionais.

Tal prática transformou a cláusula democrática em uma muralha contra golpistas facilmente contornável graças ao uso do julgamento político para substituir uma inexistente moção de censura. Há forte tendência da cláusula democrática se tornar irrelevante.

Todavia, essa postura da OEA tem outra consequência deletéria, que é a de estimular esse "modelo de ação política" acima descrito, o qual ainda terá esperança caso bem-sucedido - de ganhar legitimidade internacional.

A existência de uma cláusula democrática de acionamento imperfeito e inadequado é, em certo sentido, pior que sua inexistência, pois gera uma indesejada legitimidade internacional aos que ascenderam ao poder sem respeitar a vontade majoritária.

Janeiro: Forense, 2007, pp. 53-67, em especial p. 67.

${ }^{58}$ MOUNK, Yascha. O povo contra a democracia. Trad. de Cássio de Arantes Leite e Débora Landsberg. São Paulo: Companhia das Letras, 2019, em especial p. 37.

59 DE LA TORRE, Carlos. The streets as examples of "true" democracy? The South-American experience. Estudos Ibero-Americanos, vol. 41, núm. 2, julho-dezembro, 2015, pp. 328-350, em especial p. 348

Revista de Direitos Fundamentais \& Democracia, Curitiba, v. 25, n. 3, p. 5-31, set./dez. 2020 


\section{CONCLUSÃO: A LACUNA NA PROTEÇÃO INTERAMERICANA DA DEMOCRACIA.}

O instrumento interamericano repressivo (a cláusula democrática) tem natureza discricionária e é fortemente dependente da coloração política e da força geopolítica do Estado infrator, sendo inapropriado para os novos meios de interrupção do mandato presidencial.

Seu uso serve, na atualidade, para combater rupturas nítidas e transparentes da ordem democrática. Por isso é inadequado para corrigir sistemas eleitorais enraizados, mesmo que violadores de direitos (como a igualdade do voto) e para combater rupturas camufladas da ordem constitucional.

Os exemplos acima estudados mostram que a promoção da democracia pela OEA deve avançar e enfrentar os novos desafios, que resumo em três.

Em primeiro lugar, urge a análise da dificuldade de determinados sistemas eleitorais de espelharem as maiorias em um país, rompendo a missão primordial do direito eleitoral em democracias representativas que é transformar a vontade do eleitor em mandatos. Essa dificuldade gera a possibilidade de um programa presidencial escolhido de modo majoritário ser confrontado por outra agenda fruto de um Parlamento bicameral, escolhido em circunscrições eleitorais assimétricas, com pouco peso para "uma pessoa, um voto".

Em segundo lugar, o uso de manifestações de rua, votos de protestos (escolha de candidatos "diferentes") como forma de superação dos vícios da representação política podem representar um risco à democracia em si, fazendo renascer projetos de concentração de poder nas mãos de presidentes eleitos de forma majoritária e que estariam sendo ameaçados por um Parlamento sem representatividade.

O terceiro desafio é evitar a percepção de captura política da OEA, revelada pela ausência de acionamento da cláusula democrática, mesmo diante de situações que outras organizações ou mesmo o próprio Secretário-Geral da OEA consideraram graves do ponto de vista de respeito à democracia.

Como visto, a cláusula democrática não serve para enfrentar esses desafios. Seu uso no século XXI foi excepcional (Honduras), não tendo sido acionada em nenhum caso de interrupção de mandatos presidenciais pela via do julgamento político.

Voltando as perguntas estabelecidas na introdução, observo que a cláusula 
democrática é inapropriada para as novas crises, mas pode responder com certa eficiência a golpes militares feitos sem nenhum tido de camuflagem ou decoro. Como não é utilizada para outras formas de afronta à vontade popular, a cláusula democrática pode erroneamente sugerir legitimidade internacional a governos cujo acesso ao poder desrespeitou o direito à participação política e o devido processo legal.

Há, assim, uma lacuna na proteção interamericana da democracia, tal qual definida na Carta Democrática Interamericana. É necessário que o processo internacional de direitos humanos do tipo judiciário capitaneado pela Comissão e Corte Interamericanas de Direitos Humanos assuma a missão de escrutinar, à luz da gramática de direitos humanos, essas novas formas de interrupção do mandato presidencial, seguindo a linha já sugerida pelo Ministro Alexandre de Moraes, de não permitir a atuação arbitrária e insincera dos agentes políticos, respeitando, consequentemente, os direitos políticos e a investidura popular nas democracias.

\section{REFERÊNCIAS}

ALMEIDA, Wilson e SANTANA, Hadassah Laís. Integração e democracia: os interesses políticos locais que distorcem o direito internacional e a crise política resultante da suspensão do Paraguai do Mercosul. Revista de Informação Legislativa. Ano 51, n. 203, jul/set. 2014, pp. 91-110.

ARAUJO, Matheus Alexandre e PEREIRA, Vanessa dos Santos. Rupturas, neogolpismo e América Latina: uma análise sobre Honduras, Paraguai e Brasil. Revista Katálysis, v. 21, n. 1, , jan./abr. 2018, pp. 125-136.

BEIGBEDER, Yves. International Monitoring of Plebiscites, Referenda, and National Elections: Self-Determination and Transition to Democracy. The Hague: Martinus Nijhoff, 1994.

BOLÍVAR, Simón. Contestación de un americano meridional a un caballero de esta isla (1815). in BOLÍVAR, Simón. Doctrina del Libertador. Caracas: Fundación Biblioteca Ayacucho, 2009, pp. 18-87.

BRASIL, Mandado de Segurança n. 34.193-DF, Relator Min. Alexandre de Moraes, decisão de 7 de dezembro de 2018, DJE n² 266, divulgado em 11/12/2018.

BRASIL, Mandado de Segurança n. 34.193-DF, decisão de 11 de maio de 2016, Relator Min. Teoria Zavascki, DJE n 97, divulgado em 12/05/2016.

BRASIL, Supremo Tribunal Federal ADPF 378 MC, rel. p/ o ac. min. Roberto Barroso, j. 16-12-2015, P, DJE de 8-3-2016. 
BRASIL, Supremo Tribunal Federal, ACO n. 4.070/DF, Rel. Min. Teori Zavascki, referendo na ação cautelar, j. 5-5-2016, DJe de 21-10-2016.

BRASIL, Tribunal Superior Eleitoral, Apuração de Eleição $\mathrm{n}^{\circ}$ 1578-04.2014.6.00.0000, votação unânime, sessão de 4.11.2014.

BRASIL. Senado Federal como órgão judiciário. Sentença. Disponível em: https://www12.senado.leg.br/noticias/arquivos/2016/08/31/veja-a-sentenca-deimpeachment-contra-dilma-rousseff, acesso em 13-07-2020.

CARVALHO RAMOS, André de. Curso de direitos humanos. $7^{\text {a }}$ ed., São Paulo: Saraiva, 2020.

CARVALHO RAMOS, André de. Processo internacional de direitos humanos. $6^{\mathrm{a}}$ ed, São Paulo: Saraiva, 2019.

CARVALHO RAMOS, André de. Teoria geral dos direitos humanos na ordem internacional. 7a ed., São Paulo: Saraiva, 2019.

CARVALHO RAMOS, André de. Derechos Humanos y el Mecanismo Híbrido del Mercosur: ¿Cómo controlar la aplicación de la cláusula democrática? Revista de la secretaria del Tribunal permanente de revisión. Año 3, nº 6; agosto 2015, pp. 48-68.

CLĖVE, Clèmerson Merlin; SARLET, Ingo W. e PAGLIARINI, Alexandre Coutinho.

Direitos humanos e democracia. Rio de Janeiro: Forense, 2007.

COELHO, André. Inestabilidad política y caídas presidenciales en Sudamérica: causas y consecuencias. Revista de Ciência Política, Vol. 50, n 1, 2012, pp. 167-194.

DE LA TORRE, Carlos. The streets as examples of "true" democracy? The SouthAmerican experience. Estudos Ibero-Americanos, vol. 41, núm. 2, julho-dezembro, 2015, pp. 328-350.

Disponível em https://web.archive.org/web/20061129194810/http://www.accessdemocracy.org/library/1 923_declaration_102705.pdf

GOBAT, Michel. The Invention of Latin America: A Transnational History of AntiImperialism, Democracy, and Race. The American Historical Review, vol. 118(5), December 2013, pp. 1345-1375.

GÓMEZ MARTíN, A. La destitución de Fernando Lugo y Dilma Rousseff. Una comparación de ambas crisis democráticas desde la labor de las organizaciones regionales. Revista Integración y Cooperación Internacional, n. ${ }^{\circ} 27$, dezembro de 2018. Disponível em http://rephip.unr.edu.ar/bitstream/handle/2133/13965/Art\%C3\%ADculo\%201\%20 $\% 20$ Revista\%20Nro.\%2027.pdf?sequence=3. Acesso em 13-07-2020.

HAGOPIAN, Frances e MAINWARING, Scott P. (orgs). The Third Wave of Democratization in Latin America - Advances and setbacks. Cambridge/New York: Cambridge University Press, 2005. 
HEINE, Jorge e WEIFFEN, Brigitte. 21st Century Democracy Promotion in the Americas - standing up for the polity. New York: Routledge, 2015.

HERZ, Mônica. "Carta da OEA (1948)", in MAGNOLI, Demétrio. A história da paz, São Paulo: Contexto, 2008, p. 331-353.

HOCHSTETLER, Kathryn. Repensando o presidencialismo: contestações e quedas de presidentes na América do Sul. Lua Nova, n.72, 2007, pp.09-46.

HONDURAS, Informe de la Comisión de la Verdad y la Reconciliación (CVR). Para que los hechos no se repitan: Informe de la Comisión de la Verdad y la Reconciliación, julho de 2011. Disponível em

https://www.oas.org/es/sap/docs/DSDME/2011/CVR/Honduras/nformeCVR_TOMO1.pd $\mathrm{f}$, acesso em 13-07-2020.

https://www12.senado.leg.br/noticias/arquivos/2016/08/31/veja-a-sentenca-deimpeachment-contra-dilma-rousseff, acesso em 13-07-2020

HUNTINGTON, Samuel P. The Third Wave - Democratization in the Late Twentieth Century. Norman/London : University of Oklahoma Press, 1993.

HYDE, Susan D. The pseudo-democrat's dilemma: why election observation became an international norm. Ithaca/London: Cornell University Press, 2011.

KASAHARA,Yuri e MARSTEINTREDET, Leiv. Presidencialismo em crise ou parlamentarismo por outros meios? Impeachments presidenciais no Brasil e na América Latina. Revista de Ciências Sociais, , v.49, n. 1, , mar./jun., 2018, pp.30-54.

MENDES, Gabriel Gutierrez. O impeachment de Dilma Rousseff e a instabilidade política na América Latina: a aplicabilidade do modelo de Perez-Liñan. Revista de Ciências Sociais, v.49, n. 1, mar./jun., 2018, pp. 253-278.

MONTEIRO, Leonardo Valente. Os neogolpes e as interrupções de mandatos presidenciais na América Latina: os casos de Honduras, Paraguai e Brasil. Revista de Ciências Sociais, v.49, n. 1, mar./jun., 2018, pp. 55-97.

MONTEIRO, Leonardo Valente. Os neogolpes e as interrupções de mandatos presidenciais na América Latina: os casos de Honduras, Paraguai e Brasil. Revista de Ciências Sociais, v.49, n. 1, p.55-97, mar./jun., 2018, pp. 55-97.

MOUNK, Yascha. O povo contra a democracia. Trad. de Cássio de Arantes Leite e Débora Landsberg. São Paulo: Companhia das Letras, 2019.

ORGANIZAÇÃO DOS ESTADOS AMERICANOS, Comissão Interamericana de Direitos Humanos, Relatório sobre o Equador, 2000. Disponível em http://www.cidh.oas.org/annualrep/99eng/Chapter4a.htm, acesso em 13-07-2020.

ORGANIZAÇÃO DOS ESTADOS AMERICANOS, Comissão Interamericana de Direitos Humanos, Relatório sobre o Equador, 2000. Disponível em http://www.cidh.oas.org/annualrep/99eng/Chapter4a.htm, acesso em 13-07-2020. 
Direitos Humanos, Honduras: Derechos Humanos y Golpe de Estado. OEA/Ser.L/V/II. Doc 55, 2009, Disponível em http://www.cidh.org/countryrep/Honduras09sp/Indice.htm, acesso em 13-07-2020.

ORGANIZAÇÃO DOS ESTADOS AMERICANOS, Declaração do Secretário-Geral da OEA Luis Almagro após reunião com a Presidente Constitucional do Brasil Dilma Rousseff, em 15 de abril de 2016. Disponível em https://www.oas.org/pt/centro midia/nota imprensa.asp?sCodigo=P-044/16, acesso em 13-07-2020.

ORGANIZAÇÃO DOS ESTADOS AMERICANOS, OEA/Ser.G CPIACTA 2088/16. Sessão de 7 de setembro de 2016. Disponível em http://www.oas.org/es/council/CP/documentation/minutes/. Acesso em 13-07-2020

ORGANIZAÇÃO DOS ESTADOS AMERICANOS, OEA/Ser.P AG/RES 1 (XXXVII-E/09), de 4 de julho de 2009. Disponível em:

http://www.oas.org/consejo/sp/AG/37SGA.asp\#inf , acesso em 13-07-2020

ORGANIZAÇÃO DOS ESTADOS AMERICANOS, Relatório Final da Missão de Observação Eleitoral - Eleições gerais - Brasil - 7 de outubro de 2018 (Eleições Gerais); 28 de outubro de 2018 (Segundo Turno), 2018. Disponível em http://scm.oas.org/pdfs/2019/CP40397PRELATORIOFINALMOEBRASIL2018.pdf , acesso em 13-07-2020

ORGANIZAÇÃO DOS ESTADOS AMERICANOS, Resolução da Assembleia Geral da OEA sobre a participação de Honduras na OEA, AG/RES.1(XLI-E/11), 22 de junho de 2011. Disponível em: http://www.oas.org/council/sp/AG/41SGA.asp, acesso em 13-072020.

ORGANIZAÇÃO DOS ESTADOS AMERICANOS. OAS : 50 Years Observing Elections in the Americas, 2012. Disponível em http://207.237.157.11/es/sap/deco/docs/MOE50y e.pdf

PARAGUAI. Decisión provisional de la acción de inconstitucionalidad n. 1533.

Disponível em http://www.pj.gov.py/descargas/ID1-

317_accion_de_inconstitucionalidad.pdf, acesso em 13-07-2020

PÉREZ-LIÑÁN, Aníbal. Presidential impeachment and the new political instability in Latin America. Cambridge: Cambridge University Press, 2007.

PRONER, Carol. Golpe branco no Brasil. in PRONER, Carol; CITTADINO, Gisele;

NEUENSCHWANDER, Juliana; PEIXOTO, Katarina e GUIMARÃES, Marília Carvalho (orgs). A resistência internacional ao golpe de 2016. Bauru/SP: Canal Editora, 2016, pp. 155-159.

SCHOLLER, Heinrich. Os ajustes necessários da democracia representativa. in CLĖVE, Clèmerson Merlin; SARLET, Ingo W. e PAGLIARINI, Alexandre Coutinho.

Direitos humanos e democracia. Rio de Janeiro: Forense, 2007, pp. 53-67.

SOLER, Lorena e PREGO, Florencia. Derechas y neogolpismo en América Latina. Una 
lectura comparada de Honduras (2009), Paraguay (2012) y Brasil (2016). Historia y problemas del siglo XX, Año 10, Volumen 11, julio-diciembre de 2019, pp. 33-52.

SOUZA, André Luiz Coelho Farias de. Um Novo Modelo de Destituição de Mandatários ou a Releitura de Velhas Práticas? Reflexões sobre a instabilidade presidencial contemporânea na América Latina. Revista Brasileira de Estudos Políticos, n. 113, jul./dez. 2016, pp. 11-50.

VANDEN, Harry E. e PREVOST, Gary. Politics of Latin America - The power game. New York/Oxford: Oxford University Press, 2002

Recebido em 31/07/2020 Aprovado em 15/12/2020

Received in 31/07/2020

Approved in 15/12/2020 